\title{
SOSIALISASI DAN PENDAMPINGAN PENGISIAN SENSUS PENDUDUK 2020 ONLINE SERENTAK DI UNIVERSITAS BINA BANGSA
}

Jaka Wijaya Kusuma $^{\mathbf{1}}$, Isnaini ${ }^{2}$, Beni Junedi $^{3}$, Nurhasan Nugroho ${ }^{4}$, Ranny Meilisa ${ }^{5}$, Ulfi Jefri ${ }^{6}$ ${ }^{123456}$ Universitas Bina Bangsa Serang Banten

Email: jakawijayak@binabangsa.ac.id ${ }^{1}$,isnaini@binabangsa.ac.id ${ }^{2}$, beni.junedi@binabangsa.ac.id ${ }^{3}$, nurhasan.nugroho@binabangsa.ac.id ${ }^{4}$, ranny.meilisa@binabangsa.ac.id ${ }^{5}$, ulfi.jefri@binabangsa.ac.id ${ }^{6}$

\begin{abstract}
ABSTRAK
Sensus Penduduk Indonesia 2020 (disingkat SP2020) adalah pendataan penduduk Indonesia yang mencakup jumlah penduduk, etnis, agama, pekerjaan, perekonomian, dan lain-lain. Sensus 2020 adalah sensus yang ke-7. Dalam Sensus Penduduk kali ini ada yang berbeda, yakni Sensus Penduduk Secara Online. Kelebihannya Dapat dilakukan kapan saja secara mandiri selama periode pelaksanaan Sensus Penduduk Online, Literasi masyarakat terhadap penggunaan teknologi informasi yang semakin baik., Menumbuhkan kesadaran masyarakat tentang arti penting data, dimulai dari informasi pribadinya. Namun dalam pelaksanaannya terdapat berbagai kendala, Koneksi Internet yang tidak optimal, Belum pahamnya masyarakat dalam menggunakan Gadget dan lain-lain, sehingga diperlukannya Sosialisasi dan pendampingan langsung dalam pengisiannya.
\end{abstract}

Kata kunci: Sensus Penduduk 2020, SP2020 Online, BPS, 


\section{PENDAHULUAN}

Dalam rangka menyambut Sensus Penduduk Tahun 2020, Badan Pusat Statistik (BPS) Provinsi Banten bermaksud melakukan kegiatan sosialisasi kepada berbagai pemangku kepentingan, termasuk diantaranya civitas akademika. Civitas akademika merupakan pihak yang sangat berkepentingan terhadap suksesnya Sensus Penduduk 2020 (SP2020). Data Sensus Penduduk menjadi salah satu rujukan penting dalam banyak penelitian yang dilakukan oleh mahasiswa, dosen serta peneliti. Banyak informasi baru tentang SP2020 yang disampaikan kepada dunia pendidikan khususnya di dalam kampus. Sensus Penduduk kali ini dilakukan dengan metodologi yang baru yang belum pernah dilakukan dalam Sensus Penduduk sebelumnya. SP2020 kali ini menggunakan data registrasi administrasi kependudukan yang ada di Dukcapil Kementerian Dalam Negeri, sebagai data pre-list. Hal ini merupakan salah satu langkah demi perwujudan Perpres No. 39 Tahun 2019 tentang Satu Data Indonesia. Selain itu juga, sensus dilakukan dengan multi-moda, mulai dari Sensus Penduduk Online yang dilakukan melalui web browser yang terhubung ke internet, kemudian wawancara langsung dengan aplikasi menggunakan gawai, serta cara konvensional yaitu pendataan menggunakan kuesioner berbentuk kertas. Melalui sosialisasi Sensus Penduduk 2020 ini diharapkan seluruh lapisan masyarakat khususnya civitas akademika, dapat memahami akan pentingnya Sensus Penduduk bagi pembangunan di Indonesia. Indikator-indikator demografi yang selama ini dihasilkan BPS, selalu berbasis kepada data hasil Sensus Penduduk. Sebut saja, Infant mortality rate (IMR) atau angka kematian bayi, Life expectancy at Birth (LEB) atau usia harapan hidup sejak lahir, serta untuk penghitungan proyeksi penduduk, dan masih banyak indikator demografi lainnya yang dapat dihasilkan melalui Sensus sepuluh tahunan tersebut. Kami juga hendak mendorong civitas akademika untuk mau berpartisipasi aktif dalam Sensus Penduduk Online. Hal ini bertujuan untuk meningkatkan response rate pada kegiatan Sensus Penduduk Online yang dilakukan secara mandiri dengan masyarakat. Sehingga tercipta kesadaran dan kepedulaian masyarakat terhadap pemutakhiran data kependudukan oleh diri mereka sendiri.

\section{METODE}


Berdasarkan permasalahan di atas, salah satu solusi yang dapat dilakukan adalah melakukan sosialisasi dan Pendampingan Civitas Akademika dalam dalam bentuk kegiatan BPS Goes To Campus. Kegiatan ini diberikan kepada Mahasiswa Universitas Bina Bangsa oleh Narasumber dari BPS Banten dan Pendamping dari Dosen-dosen Univeristas Bina Bangsa. Pemateri menyampaikan tentang pentingnya Data Statistik Kependudukan dalam segala bidang. Kegiatan pengabdian ini dilaksanakan selama satu hari Full. Kegiatan ini di awali dengan pemaparan materi dari pihak BPS Banten dan dilanjut dengan Pengisian SP2020 Online secara serentak dimana semua mahasiswa dalam pengisiannya didampingi oleh Dosen-dosen dari Universitas Bina Bangsa. Bentuk kegiatan Sosialisasi SP2020 dilaksanakan dalam suatu ruangan Aula dengan Peserta sebanyak 300 audience dan tersedianya peralatan audio dan visual untuk menunjang presentasi. Kegiatan diisi dengan seminar tentang SP2020, yang diselingi dengan kegiatan kuis dengan hadiah menarik dan di akhir acara, semua Audience mengisi SP2020 Secara Serentak melalui Gadgetnya masing-masing Kegiatan Sosialisasi SP2020 ini diikuti oleh sejumlah civitas akademika di lingkungan kampus, mulai dari mahasiswa, dosen serta pihak penyelenggara.Sebelumnya Seluruh mahasiswa Universitas Bina Bangsa di ajak untuk mengikuti kegiatan ini secara daring melalui Instagram Kampus, dimana mahasiswa yang berminat di wajibkan untuk mengisi form online yaitu : bit.ly/bpsgoestouniba2020 setelah mengisi online mahasiswa langsung di undang secara resmi melalui Messenger dan dikirimkan Rundown Acara.Peserta pun di wajibkan membawa Kartu Keluarga.

\section{Flyer "BPS Goes To Campus"}

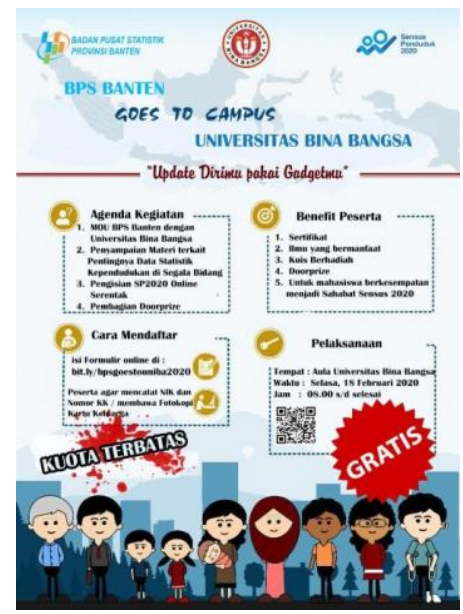


Dari Pihak BPS Banten, kami melakukan penjajakan sebelumnya. Apakah dari pihak Kampus bisa berkontribusi dalam kegiatan ini terutama untuk menunjang kegiatan Pengabdian Masyarakat. BPS Banten merespon dengan merangkul Dosendosen Universitas Bina Bangsa untuk ikut serta mendampingi mahasiswa dalam kegiatan ini.

\section{HASIL DAN PEMBAHASAN Pelaksanaan Kegiatan}

Kegiatan kami ini merupakan suatu program Pengabdian Kepada Masyarakat (PKM) dimana tujuan kami agar mahasiswa atau Audience mampu mengetahui informasi tentang kegiatan SP2020, Mengetahui output yang dihasilkan dari kegiatan SP2020, Memiliki pengetahuan tentang data kependudukan sehingga dapat digunakan dalam penelitian ilmiah, Mendukung kegiatan SP2020 dengan cara menjadi " Relawan atau Agent" untuk mengajak masyarakat berpartisipasi dalam kegiatan Sensus Penduduk Online, Mengetahui serta yakin terhadap keamanan dan kerahasian data individu yang mereka berikan dalam kegiatan Sensus Penduduk 2020.

\section{SUSUNAN ACARA}

BPS GOES TO UNIVERSITAS BINA BANGSA 2020

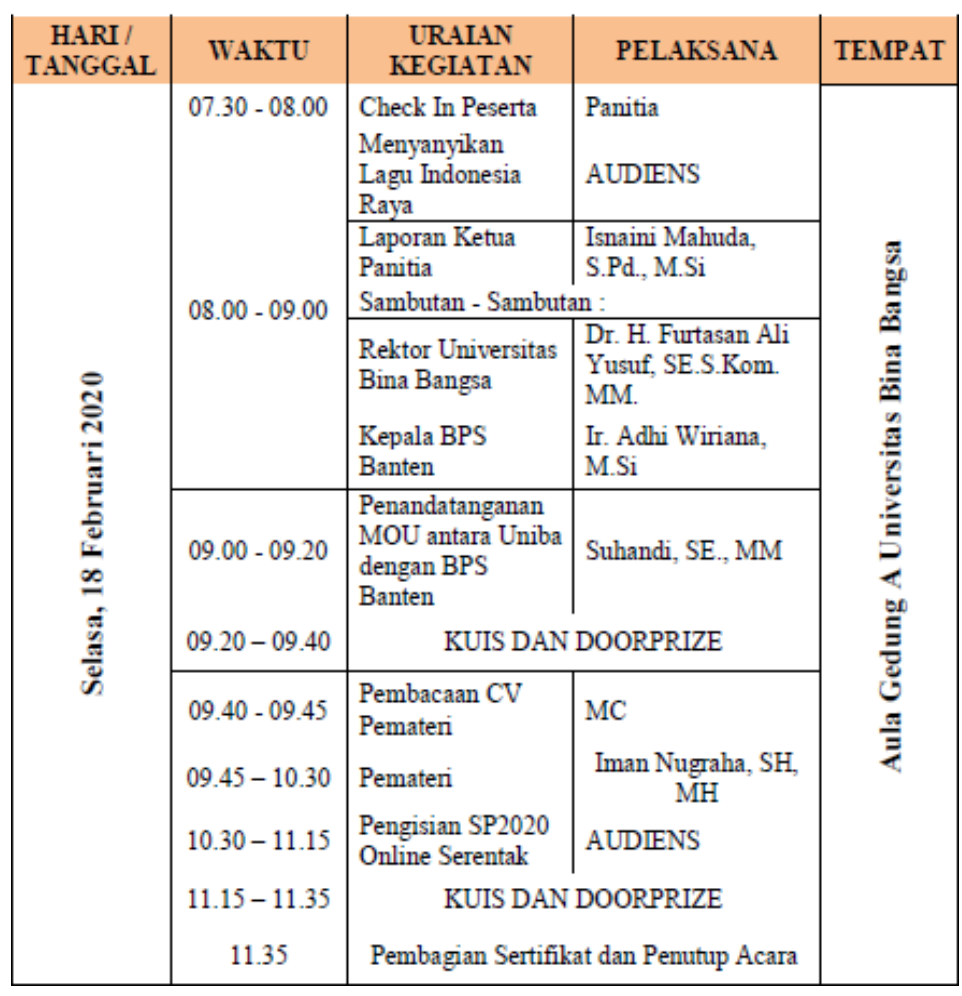


Kegiatan yang dilaksanakan hari Selasa, 18 Februari 2020 ini menggunakan Presentasi dimana materi disampaikan sesuai tema terkait Sensus Penduduk. Adapun materi yang pertama disampaikan Iman Nugraha, $\mathrm{SH}, \mathrm{MH}$ memberikan pemahahan tentang pentingnya Data Statistik Kependudukan dalam Segala Bidang terutama dalam bidang Pendidikan. Untuk pemateri yang kedua diisi oleh Wahyudi, SST. Materi yang disampaikan mengenai "Tata Cara Pengisian Online Sensus Penduduk 2020 melalui Gadget”. Materi ini memberikan pemahaman kepada peserta bagaimana cara Pengisian online Sensus Penduduk 2020. Tujuannya agar Audience nanti bisa mengisi sendiri tanpa ada pendampingan ketika berada di Masyarakat. Kegiatan terakhir yakni pengisian Online Secara Serentak dimana seluruh Audience membuka Gadgetnya, aktifkan data selularnya dan langsung buka browser ke alamat sensus.bps.go.id dan memulai mengisi data Pribadinya masing-masing.

Foto-Foto Kegiatan
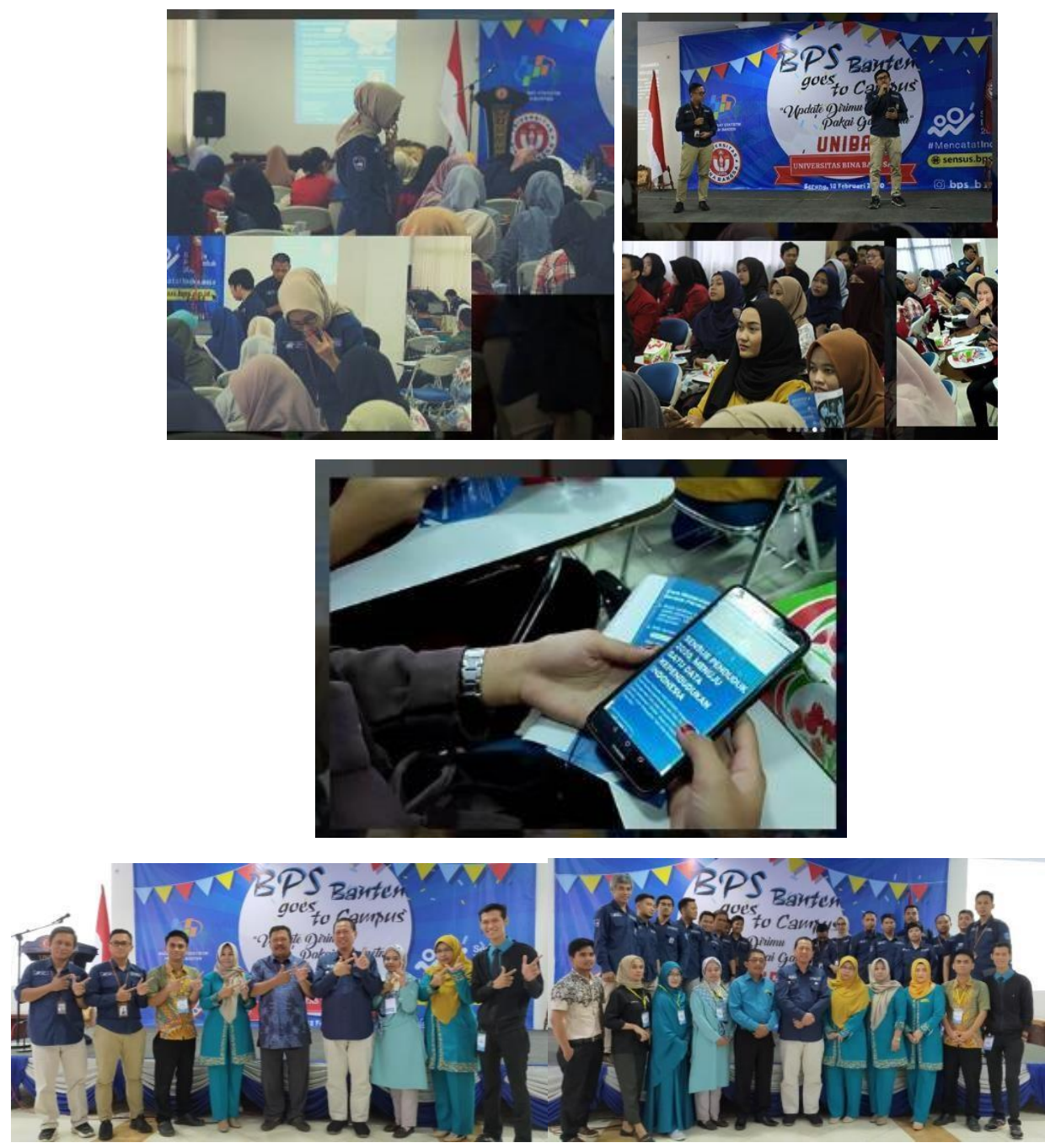


\section{Evaluasi Kegiatan}

Untuk mengevaluasi keberhasilan kegiatan dibuat beberapa indikator dengan rincian sebagai berikut.

\section{Evaluasi Tahap Pertama}

Evaluasi ini dilakukan pertama, dimana kami melakukan penjajakan setelah pihak BPS Banten mengirim Proposal terkait kegiatan Sosialisasi ini. Dalam tahap ini terjalin komunikasi yang baik antara Pihak BPS Banten dan Universitas Bina Bangsa. Sehingga pembagian peran berjalan dengan lancar. Tahap Pertama sukses dilaksanakan

\section{Evaluasi Tahap Kedua}

Evaluasi tahap kedua dilakukan setelah Undangan dan flyer tersebar melalui Instagram Kampus. Indikator keberhasilannya ialah Peserta Memenuhi Batas Minimal dan tidak melebihi maksimal Kapasitas. Seiring waktu berjalan, diluar dugaan jumlah peserta mencapai batas maksimal yakni 300 Peserta. Sehingga 3 Hari Sebelum pelaksanaan Pendaftaran Online kegiatan ini sudah ditutup. Tahap Kedua pun sukses dilaksanakan

\section{Evaluasi Tahap Ketiga}

Evaluasi tahap ketiga dilakukan setelah kegiatan terlaksana. Indikatornya Audience menjadi paham tentang Pentingnya Sensus Penduduk dan bisa melaksanakan Pengisian Sensus Penduduk secara online dengan Mandiri. Dari tanggapan beberapa Audience kegiatan ini Sangat memberikan Edukasi kepada mahasiswa dan dalam Prakteknya mahasiswa mampu mengisi Sensus Penduduk Online melalui Gadgetnya. Pihak BPS Banten pun memberikan pengawasan terkait kesuksesan kegiatan ini. Dan pihak BPS menyampaikan secara garis besar kegiatan ini sukses. Walau ada sedikit kendala terkait jaringan koneksi tapi secara keseluruhan mahasiswa mampu melaksanakannya. Dari Pihak dosen pun terbukti dengan tidak terlalu banyak mahasiswa bertanya ketika pelaksanaan pengisian Sensus. Sehingga dalam pendampingan dosen-dosen Universitas Bina Bangsa dibuat santai dan tidak terlalu sibuk. Hal ini menandakan kegiatan ini Berjalan dengan Baik dan sukses. 


\section{KESIMPULAN}

Berdasarkan dari uraian di atas sebenarnya mahasiswa paham akan pentingnya Data Statistik Kependudukan, hanya saja kurang adanya penekanan dan pengulangan lebih luas terkait pemahaman tersebut. Dan ternyata dalam pengisian Sensus Penduduk pun yang dilaksanakan secara Online jauh dari kata Ribet. Sangat Mudah sekali. Hanya butuh waktu beberapa menit saja untuk mengisi Sensus secara online. Bahkan mahasiswa pun dalam akhir kegiatan siap membantu mensosialisasikan pengisian ini kepada Lingkungan sekitarnya masing-masing.

\section{DAFTAR PUSTAKA}

Badan Pusat Statistika. 2020. Pedoman Teknis BPS Provinsi \& BPS Kab/Kota.

Jakarta:BPS Indonesia

Lucas, David. 1990. Pengantar Kependudukan.Jogjakarta :Gajah Mada University Press

Mantra, Ida Bagus. 1985. Pengantar Studi Demografi. Jakarta: Nur Cahaya 